\title{
Optimum Design for Multi-angle Kitchen Grater Mechanism for Biodegrading Kitchen Waste
}

\author{
Zol Bahri Razali ${ }^{1, *}$, Abdul Rahim Abdul Hasim ${ }^{1}$, and Mohd Hisam Daud ${ }^{1}$ \\ ${ }^{1}$ Robotics and Automation Technology, Faculty of Engineering Technology, Universiti Malaysia \\ Perlis, 02100 Padang Besar, Perlis, Malaysia
}

\begin{abstract}
The study presented in this report is regarding on the conceptual design of the grater machine which meant to shred food wastes into small and fine size particle. This study will focus on the waste management factor of the food waste produced in the home kitchen. A study is conducted to compare the most suitable material and geometric shape of the grating blades by comparing with similar existing devices in the market. The chosen material and blade design are to be evaluated for its characteristics and performance by using the FEM method. The analysis is taking all the constraints regarding the design as well as its advantages are to be considered in designing a new grating blade for the optimum end product making. This design derived through in the consideration for the home application rather than domestic use. This brings the meaning that the compact and small size design. With the detailed evaluation of the stress reaction on the blades to provide the safety and sustainability factor of the device as well as the people that is using the device.
\end{abstract}

\section{Introduction}

The "Grater" machine (also known as a shredder) is a kitchen utensil used to grate foods into fine pieces [1]. This study will focus on the waste management factor of the food waste produced in the home kitchen. The project is to analyse the optimum design of Multi-angle Kitchen Waste Grater machine. For this intention, several types of existing grater blade design in the market are to be evaluated for its characteristics. All the constraints regarding the design as well as its advantages are to be considered in designing a new grating blade for the optimum fineness end product and the speed of grating capacity. This design should consider for the application in the house which mean it should be smaller size and the safety precaution factor of the operator and other peoples in surrounding area must be placed at the top priority.

The main objective is about the kitchen waste management where it is to be recycled and reuse for the purpose of agriculture. Today's growth of our country shows the rapid increment of waste producing amount. The waste producing rate is 19,000 tons of garbage a day and the number getting increase and estimated will approach 30,000 tons per day by year 2020 [2]. This scenario has put a major constraint in managing the resources for the landfill. The government has launched the Solid Waste Management Act and Public

\footnotetext{
* Corresponding author: zolbahri@unimap.edu.my
} 
Cleansing 2007 (Act672) which had been implemented since 1st September seen tremendously a great effort to encourage the public in adopting recycling. Other developed countries like the United States, Japan and most of the European countries has long been practiced the recycling method to reduce the environmental loadings and natural resources consumption [3]. It is the time where recycling practices of waste produced at home become a new branch of an engineering equipment production to be explored in line with current needs [4].

The analysis consists of mincing mechanism design force analysis and the simulation of the grater. For this purpose, several samples of existing grater blades will be analysed. The main focus is where it should begin by mean of analyse the design of grate mechanism material and propose the new design which offer the improvement in the qualities and durability. The mechanical properties of the food variants will be taken in consider for determining the required strength of the greater material or the blades [5]. This includes every scope of human consumption varies from organic based product such as vegetables along with its wastes which have the lower hardness property for livestock material such as meat and bones which are the hardest materials in human food classification.

\section{Literature review}

Utilizing or recycling the food waste materials have inspired the invention of a grater machine to decomposition the kitchen waste to a suitable and fast dissolve to become agricultural fertilizer. A good blade design to shreds the organic materials is important to result a fine material for composting. It is also meant that the blade should also bear in working with the varied types of waste ranging from plants to livestock products. The market nowadays has many types of grater machine and this is just another innovation which may vary the choices available.

The design analysis will be based on the varied approaches that designer used, and using the thinking that have been arisen in design research. The logic will gives the lead in describing the reasoning in design. A 'sparse' description which comes from logic will opens the way to explore the variants of the design to be differ from other point of features and advantages [2]. The reasoning patterns that usually used in problem solving of the a set of unknowns and known are described as such equation:
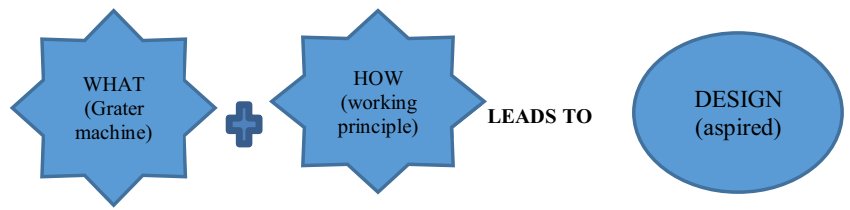

Fig. 1. The transformation of the problem solving method with regards to the current situation

\subsection{Basic concept of food grater.}

The existing products of grater only concerning to the small application in the kitchen, for cutting edges, used for grating cheese and other foods [5]. To expand the usage for home application of handling food waste, the similar equipment used in certain huge applications such as waste management center should be taken in consider. The grater machine should have the high capacity rate of processing and must be able to withstand the greatest hardness of the food material which are represented by the poultry products such as animal bones. 


\subsection{Grater blades materials.}

When handling with food based material, the best and most common material used is the stainless steel. Referring to Table 1, stainless steel-430 type is commonly used for applications such as equipment enclosures and housings. For cutting mechanism applications, the hardened martensitic stainless steel-316 is likely chosen. The Stainless Steel-316 is the one classified as the "Food Grade" type. Where the applications involve with high temperatures, the non-hardened ferritic and austenitic types of stainless steel which having the higher duplex strength is the most suitable to be used [6].

The material selection is crucial to avoid weaknesses in the design. In this case it does majorly refer to the corrosion from being occur and the stand ability to what it purposed. Better surface finish will influence the functional performance. It also makes the device easy to clean, thus keeping away the risk of corrosion. The several types of stainless steel usually used in food processing equipment is as shown below together with its typical applications.

Table 1. Types of Stainless Steel and its typical applications

\begin{tabular}{|c|l|}
\hline Type & \multicolumn{1}{|c|}{ Applications } \\
\hline $\mathbf{4 2 0}$ (Martensitic) & Spatulas, Professional knives, Cooks, etc. \\
\hline $\mathbf{4 3 0}$ (Ferritic) & $\begin{array}{l}\text { Moderately corrosive environment (e.g. dry foods, fruits, vegetables, } \\
\text { drinks, etc.), panel (i.e., components that require weldability or little } \\
\text { formability), table surfaces or cladding equipments. }\end{array}$ \\
\hline $\mathbf{3 0 4}$ (Austenitic) & $\begin{array}{l}\text { Pipework, machinery parts (i.e. components requiring some formability or } \\
\text { weldability), vats and bowls,. Greater corrosion resistance to 430. }\end{array}$ \\
\hline $\mathbf{3 1 6}$ (Austenitic) & $\begin{array}{l}\text { More corrosive foods (e.g. meat/blood, foods with moderate salt contents) } \\
\text { components, which requires frequently clean, not under excessive stress } \\
\text { and without stationary solids. }\end{array}$ \\
\hline $\mathbf{1 4 5 3 9}$ & $\begin{array}{l}\text { Corrosive foods (e.g. hot brine with solids that act as crevice forms, } \\
\text { stagnant and slow moving salty foods). }\end{array}$ \\
$\mathbf{1 4 6 6 2}$ (Duplex) & $\begin{array}{l}\text { Corrosive foods (e.g. hot brine in solids, stagnant and also slow } \\
\text { carrying salty foods). Higher strength when compared with austenitics. } \\
\text { High stress corrosion cracking resistance within salt merchandise at } \\
\text { elevated temperatures. }\end{array}$ \\
\hline $\begin{array}{c}\text { 6\%Mo.Types } \\
\text { (Austenitic) }\end{array}$ & $\begin{array}{l}\text { Corrosive foods (e.g. hot brine in solids, that act equally crevice } \\
\text { formers, stagnant in addition to slow taking salty foods). Good stress } \\
\text { corrosion cracking resistance within salt merchandise at elevated } \\
\text { temperatures. Used in steam heating and hot performs circuits, hot water } \\
\text { boilers, etc. }\end{array}$ \\
\hline
\end{tabular}

\subsection{Grater blades design.}

For soft solid surfaces separating work, the local speed of the material passing through the cutting blades will be determined by the normal and tangential forces of an element of a blade material. The ratio of 'slice' and 'push' velocities, which is defined by $\xi$. Lower the $\xi$, the greater the force reacts at the blade tip and will increase the damage to the cut surfaces. The forces of reaction also vary depends to the blade curvature which will be discussed in more details later. The analysis of existing blade design will be concluded to establish a new design which improves the constraints found [7].

Wherever the intention is, the slicer is made from steel rather from any other materials and for this case, the circular plate with plural shredding blades formed by bending a small spaced section up through the plate by a punching form method which create a hole right 
behind each blade. The shredder will strips the food product into slices where then will pass through the hole to another side of the plate (to the discharge outlet).

This kind of device (Figure 2) seems to be effective to a soft solid shredding like vegetable. For a harder solids like meat and bones, it does not suitable and may cause damage to the machine during operation.

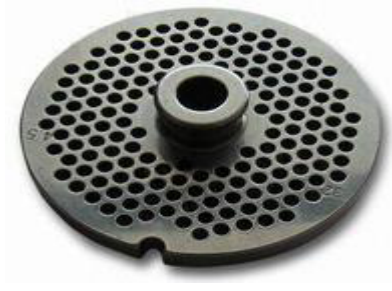

Fig. 2. Rotating Shredder/Slicer Plate [2]

The tougher and heavier duty food shredder blades come in a rotating knife blade form. This shredder assembly (Figure 3) includes the freeing jams-impact mechanism. This mechanism stores the energy in its rotating elements which sourced from the driven motor and being transmitted to the cutting blades which reacts with the materials that are going to be shredded. The cutting process will continue going to the food reached the desired size of particles which been determined through the hole size of the screen plates at the bottom of the chamber. The desired size particles will pass through the screen once meet the size to the outlet of the machine where the bucket is provided.

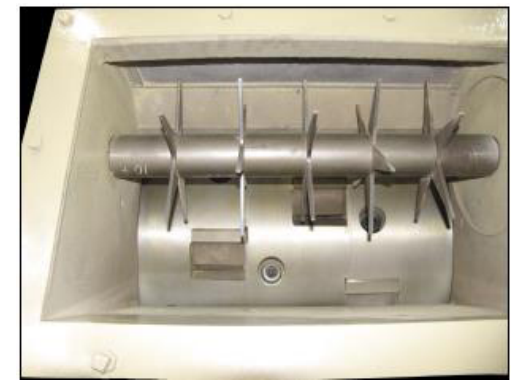

Fig. 3. Rotating Shredder/Grater Blade Types [2]

\section{Methods and materials}

\subsection{Properties of food material.}

The data of various foods modulus of elasticity, as shown in Table 2 has been collected to determine the ultimate forces that the grater blades will handle. The variants are from the soft solid like vegetables and to the hardest possible materials like animal bones. The table shown next give the values of the specific limits of forces required for varying types of foods. 
Table 2. Variety of food material mechanical properties

\begin{tabular}{|l|c|}
\hline \multicolumn{1}{|c|}{ Food Material } & Modulus of Elasticity, E (MPa) \\
\hline Onions & 0.000284 \\
\hline Corn kernels & 219 \\
\hline Apple & 0.00014 \\
\hline Meat & 3.15 \\
\hline Fish (frozen) & 0.005 \\
\hline Potato & 5.2 \\
\hline Wheat & 239 \\
\hline Carrot & 0.004 \\
\hline Bones & 275.8 \\
\hline
\end{tabular}

\subsection{Residual stresses in grater blades.}

The material structural components and engineering properties such as distortion, fatigue life, dimensional stability, the resistance to corrosion and brittle fracture are significantly influenced by residual stresses [7]. The design process indeed requires to accounting the residual stress analysis as compulsory to produce the final result of optimum reliability under actual working conditions. In cyclic loading fatigue $(\mathrm{N}>106$ cycles $)$, the residual stresses effect is comparable to the stress concentration effect. Because the residual stresses do not cause by the loads, it has to be globally balanced and can be expressed in the equation as follow;

$$
\int \sigma d A=0
$$

\subsection{Stress analysis and result.}

The development and evaluation of finite element models of grating mechanism for the cutting and rotating effects will be considered in the thesis. To calculate the original stress, the finite element analysis and modelling where the displacement boundary conditions would be the smoothed data attained from the measurements. This data can be easily described as the input to the finite element modelling.

The theories relate upon the basic assumption that the energy required to produce a change in its length, $\mathrm{dL}$ for a particle of a specific size dimension of $\mathrm{L}$, is given as a simple power function of L. With the consideration of Kick's and Rittinger's Law, leads to:

$$
E=E \mathrm{i}(5 / L 2) 1 / 2\left[1-\left(1 / q^{1 / 2}\right)\right.
$$

\subsection{Finite element analysis modeling.}

To visualize the model for the finite element analysis, a simple model of a rotating solid disc and an annulus with the same dimensions as the grater blade to be analysed. Both the solid disc and an annulus make the model exactly represent the grater blade. It will also be modeled asymmetrically with 3-D eighth model. For radial stress calculation, the term can be defined by such expression;

$$
\sigma r r=\frac{(3+v)}{8}\left(\rho b^{2} \omega^{2}\right)\left[1-\frac{r^{2}}{b^{2}}\right]
$$

where, $v=$ poisson ratio for the blade material.

$\rho=$ the mass density of the blade material 


$$
\begin{aligned}
& b=\text { disc outer radius } \\
& \omega=\text { angular velocity }(\mathrm{rad} / \mathrm{sec}) \\
& r=\text { arbitrary radial position }
\end{aligned}
$$

\subsection{Rotating solid disc analysis.}

Here the illustration the will be applied by open up the hand calculations used for the finite element analysis results validation, then the parameters and the computer model are shown and discussed. Finally, the axisymmetric model results will be compared with the hand calculations. For solid rotating disc, the exact hand calculations are as cited in Boresi and Schmidt [8]. The hand calculations represent the displacements and stresses of a rotating solid disc at about its center. Then, the results obtained from these hand calculations are compared with the results of computer model as an axisymmetric model. The following Eq. 4 is used to define the radial stress, $\sigma_{\text {rr }}$, along any arbitrary radial position, $r$, in a solid disc rotating about its center.

$$
\sigma_{r r=\frac{(3+v)}{8}}\left[1-\frac{r^{2}}{b^{2}}\right] \rho b^{2} \omega 2
$$

and the arbitrary radial position of the radial displacement is found as the Eq. 5:

$$
u=\frac{\left(1-v^{2}\right)}{8 E} \rho r^{3} \omega^{2}+C_{I} r+\frac{1}{r} C_{I I}
$$

Where $C_{I}$ and $C_{I I}$ area products of integration constants and this is the application for a solid disc only.

\section{Results and discussions}

\subsection{Nominal dimensions and parameters of a typical cut-off grater/cutting blade.}

There are many dimensions and parameters of a typical cut-off cutting blade which can be seen in Figure 3. Because the dimensions and parameters can be divided into two criteria, the parameters are given as:

i) Dimensions of the cutting blade as a whole.

ii) Dimensions of the cutting blade's rim or outer area.

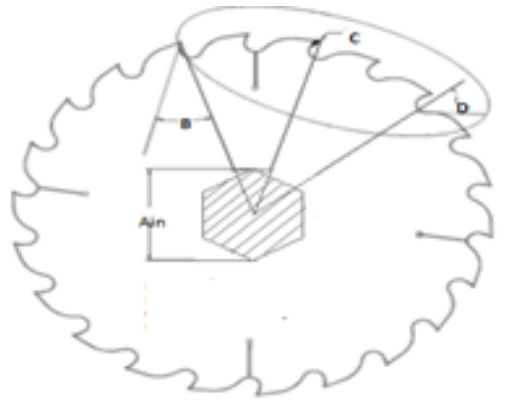
A. Collar diameter
B. Hook angle
C. Blade radius
D. Ramp angle

Fig. 4. Typical nominal parameters of a typical circular cut-off cutting blade 
Dimensions of the cutting blade as a whole. Cutting Blade as a whole refers to the Figure 4 above where " $A$ " is the collar diameter. This is where to fix the cutting blade into the shaft or the arbor of the grating machine. The arbor is a 12 inch length which can fix a number of 6 blades with a spacer in between of each blade, hexagonal shape as to improve the driven force to the blade. There are two rows of blades facing each other and the blade arrangement are alternately in between the opposite blades. Makes the whole area are included in the cutting mode during the operation. The end of both shafts will be extended out from the box. This section is to be attached to the gearing mechanism to enable the same angular velocity for both shafts. But the gearing mechanism and the driver will not be included in this design as the main objective only focus to the grater mechanism only. The arrangement of this grater blade only together with the shaft or arbor is as shown in Figure 5 .

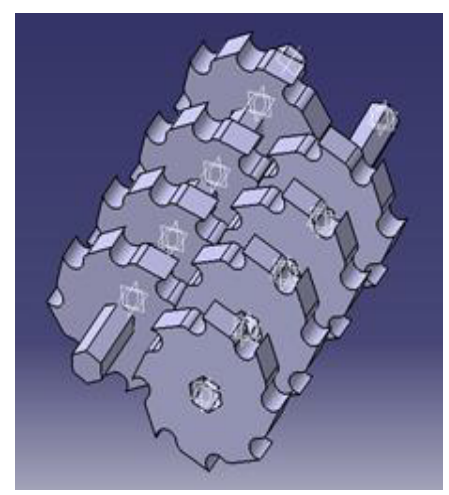

Fig. 5. The concept of grater blades arrangements

\subsection{Grater blade outer area.}

It is regarded the outer rim area and it represents the dimensions of the cutting teeth, gullets, shoulders, cutting teeth pockets, and stop hole radii. Dimension "A" in Figure 4 is the length of the cutting teeth, measured from a tooth's bottom side to the outermost point on the cutting blade. Dimension " $\mathrm{B}$ ", is the gullet radius, which brings the meaning of the radius of the designed area to cope the cutting action dust during the cutting operation and releasing the dust after that when the cutting tooth passed through the material. Dimension " $C$ " is the shoulder relief angle. Furthermore, the shoulder relief angle provides the rise to the dimension " $\mathrm{D}$ ", which is the shoulder radius that define the fast dropping off-slope radius behind the shoulder that leads towards the preceding gullet.

\subsection{Axisymmetric model of solid disc.}

The results of the radial stress computer axisymmetric-model are shown in Figure 6. Here, the radial stress is displayed in colours which are defined by the key legend at the top left of the picture. This is the figure that represents an axisymmetric model of a solid rotating disc at about its center. 


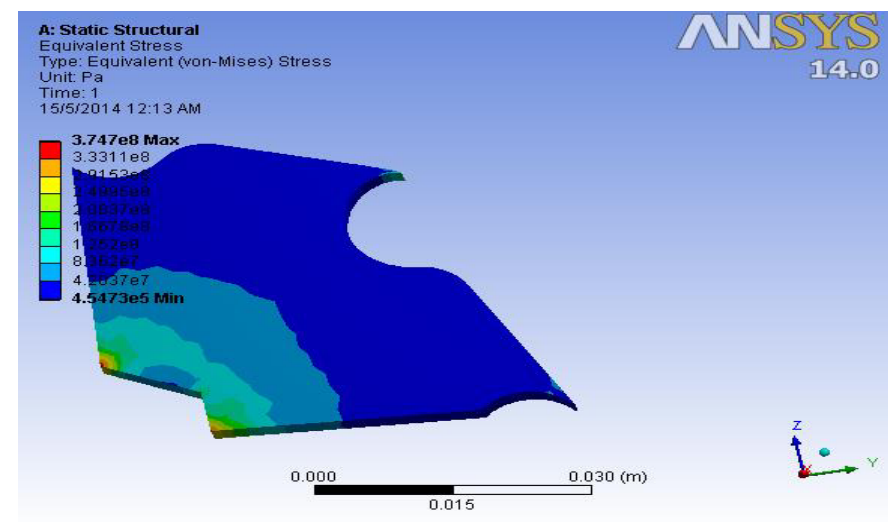

Fig. 6. Axisymmetric model showing radial stress (S11) in solid disc.

\subsection{Comparing radial stress.}

Here, the hand calculated results for the radial stress is to be comparable to the computer results, the two results did match quite well alike. For the signal-to-noise ratio between the 40 axisymmetric model results and the hand calculations of the radial stress is $3747000 \mathrm{~Pa}$. Thus, the maximum error for the both results is very low at $9.18 \mathrm{E}-05 \mathrm{MPa}$ and the error standard deviation is calculated at 0.0001585 for a maximum stress of $374.7 \mathrm{MPa}$. These statistical analysis values are obtained from the hand calculations and the computer results comparison proves that the computed results are very accurate and extremely well represent a rotating solid disc. The plots of the results of hand calculation results and the finite element analysis are as shown in Figure 7.

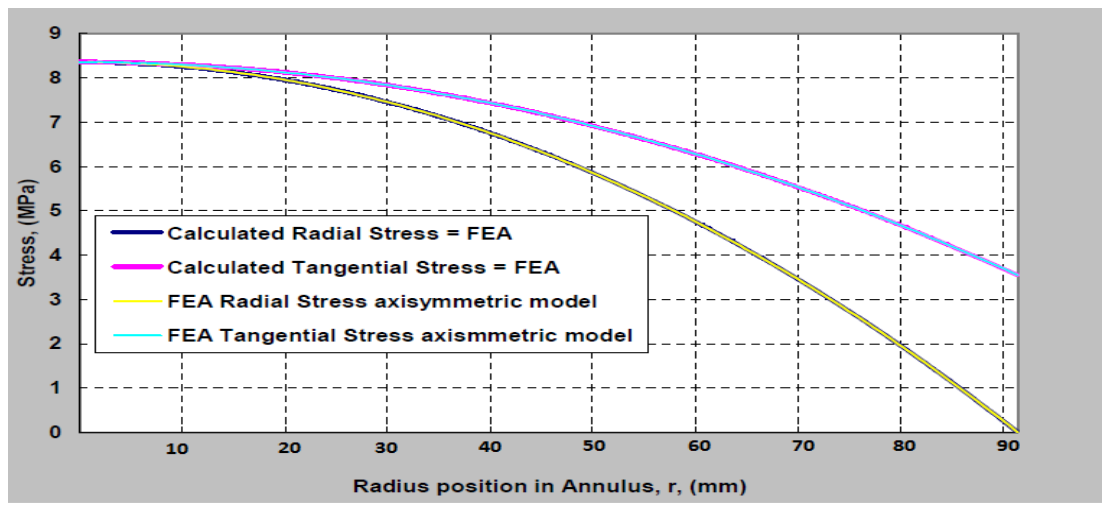

Fig. 7. The radial and tangential stress in a 4 -in $(100 \mathrm{~mm})$ radius solid disc

\subsection{Comparing radial displacement.}

The radial displacement results between the hand calculations and the axisymmetric model results are compared. The radial displacement signal-to-noise ratio is 117,500 with a maximum error between the two cases of 3.30E-08 mm and a maximum displacement of $0.004 \mathrm{~mm}$. The estimated error standard deviation is 3.40E-08. As seen in Figure 8, the solid disc radial displacement of a four inches diameter flats off at its outer edge. The difference between the axisymmetric results and the hand calculation for radial displacement on the plot is negligible. 


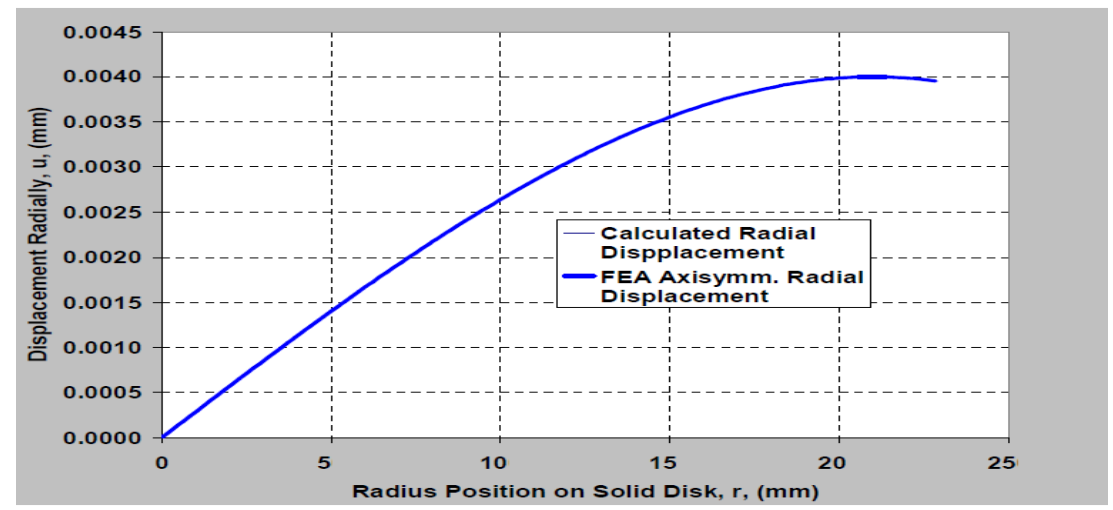

Fig. 8. The hand calculation of the radial displacement

\subsection{Results of spinning grater blade.}

The results obtained from the spinning blade body in Ansys shows the value of stresses occurred in the model of the solid grater blade disc.. The maximum and minimum stresses are as seen in the table gives the value of $374.7 \mathrm{MPa}$ and $0.4547 \mathrm{MPa}$. By comparing these values to the grater blade material properties, which is given by the $250 \mathrm{MPa}$. It is assumed that this grating mechanism could reach the optimum working performance and will not get failed upon the most extreme food material in its operations. The contour of the equivalent stress occurs in the solid blade element as in Figure 8, only shows a small gradient of high stress locating at the center of the bore which is precisely designed in hexagonal shape to capture the driven inertia force transmitted from the driving device such as motor very effectively and with high durability.

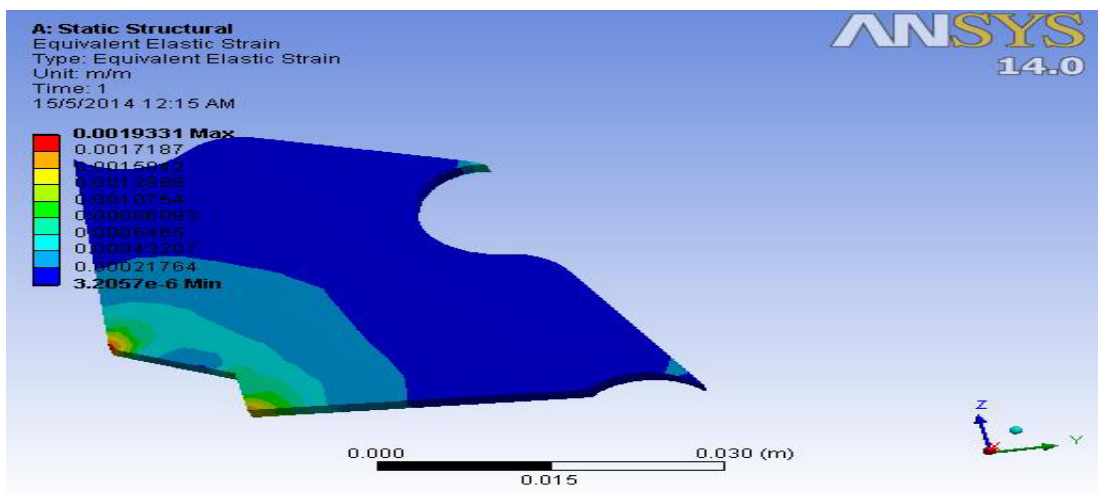

Fig. 9. The Ansys Elastic Strain Occurred Results of the Model during operations

\section{Conclusion}

The research overall has resulted in better understanding of a grating blade mechanism. This paper has given the detail views about the associated stresses that occur in the element. This will lead to the main objective which to create a new food waste grating device for home application. The radial stresses acting to the model is that obtained through computer 
analysis then compared to another method of hand calculation to see its discrepancies as well to validate the results.

The study conducted is able to compare the most suitable material and geometric shape of the grating blades by comparing with similar existing devices in the market. The proposed material and blade design have evaluated their characteristics and performance by using the FEM method. By taking all constraints regarding the design as well as its advantages are to be considered in designing, a new grating blade for the optimum multiangle end product is able to be proved. The problem of solid disc that associates with the rotation and cutting loads, the length of the specimen to be cut and the residual stress has also been solved in this research.

This work was financially supported by the Universiti Malaysia Perlis Seed Money (9014-00034).

\section{References}

1. M. Fujii, Resour. Conserv. Recy., 49, 564 (2012)

2. Z.B. Razali, N.A. Mat Nawi, Automated Segregating Device for Reuse and Recycle Waste (LAP, Germany, 2013)

3. http://en.wikipedia.org/wiki/Grater Retrieved on 24 October 2013.

4. Z.B. Razali, G.B. Lee, High-End Technology for Effective Glass Manufacturing Industry (LAP, Germany, 2013)

5. P.W. Jeffrey, Designing an Appropriate Technology Shredder in a Developing Country, Master thesis (University of St. Thomas, Minnesota, 2005)

6. D. Kees. Design Stud., 32, 521 (2011)

7. N.S. Rossini, Mater. Design, 35, 572 (2011).

8. B. Ponton, Finite Element Analysis of Industrial Circular Sawblade with Respect to Tensioning, Rotating, Cutting, and Expansion Slots, Master thesis (Vir. Poly. Institute and State U. 2007).

9. G.D. Saravacos, Mechanical processing equipment (Kluwer Acad. Pub, 2002)

10. A. Boresi, R. Schmidt, Advanced Mechanics of Materials (Wiley, New York, 2003) 